\title{
1-Metilciclopropeno na manutenção da qualidade pós-colheita de taperebá (Spondia Mombin L.)
}

\author{
Alex Guimarães Sanches ${ }^{1}$, Maryelle Barros da Silva ${ }^{1}$, Elaine Gleice Silva Moreira ${ }^{1}$, Jaqueline \\ Macedo Costa ${ }^{1}$
}

${ }^{1}$ Universidade Federal do Pará, Campus Altamira, Altamira, Pará, Brasil. E-mail: alexsanches.eng@gmail.com, maryellebarros@bol.com.br, elaine.moreira230@gmail.com,jackmacedo@gmail.com

Recebido: 26/12/2016; Aceito: 17/05/2017.

\section{RESUMO}

A vida útil pós-colheita do taperebá é muito curta mesmo em condições de refrigeração, assim o presente trabalho tem por objetivo avaliar a influência de diferentes concentrações de 1-metilciclopropeno (MCP) sobre a conservação e preservação da qualidade deste fruto visando maior tempo de comercialização na forma in natura. Adotou-se um delineamento experimental inteiramente casualizado em arranjo fatorial $4 \times 5$ com cinco repetições. A cada três dias os frutos de cada tratamento foram avaliados quanto à perda de massa fresca, firmeza da polpa, pH, o conteúdo de sólidos solúveis, teor de vitamina C, acidez titulável, índice de maturação e taxa respiratória. Os resultados demonstraram efeito significativo em todas as características avaliadas tanto no tempo de armazenamento quanto entre os tratamentos. De modo geral, o 1-MCP controlou as alterações fisiológicas nos frutos principalmente sobre os atributos quantitativos de sólidos solúveis, firmeza da polpa, acidez e teor de vitamina $\mathrm{C}$, pH e perda de massa fresca. Concentrações entre 100 e $150 \mathrm{mg} \mathrm{L}^{-1}$ de 1-MCP são recomendadas para a pós-colheita do taperebá por promover maior conservação durante o armazenamento refrigerado dos frutos.

Palavras-chave: Spondia mombin L., amadurecimento, conservação, fruta tropical.

\section{1-Methylcyclopropene (MCP) on quality post-harvest maintenance of taperebá (Spondia Mombin L.)}

\begin{abstract}
The post-harvest shelf life of taperebá is very short even in refrigerated conditions, so the present work has the objective of evaluating the influence of different concentrations of 1-methylcyclopropene (1-MCP) on the conservation and the quality of this fruit aiming at a longer commercialization time in natura. A completely randomized experimental design was used in a 4x5 factorial arrangement with five replications. Every three days the fruits of each treatment were evaluated for loss of fresh mass, pulp firmness, $\mathrm{pH}$, soluble solids content, vitamin $\mathrm{C}$ content, titratable acidity, maturation index and respiratory rate. The results showed a significant effect on all the characteristics evaluated both in storage time and between treatments. In general, 1-MCP controlled the physiological changes in fruits mainly on the quantitative attributes of soluble solids, pulp firmness, acidity and vitamin $\mathrm{C}$ content, $\mathrm{pH}$ and fresh weight loss. Concentrations between 100 and $150 \mathrm{mg} \mathrm{L}^{-1}$ of 1 -MCP are recommended for the post-harvest of taperebá by promoting greater conservation during refrigerated storage of fruits.
\end{abstract}

Key words: Spondia mombin L., ripening, conservation, tropical fruit. 


\section{Introdução}

O taperebazeiro (Spondia mombin L.) é uma das espécies frutíferas utilizadas nos sistemas agroflorestais (SAF’s) no Estado do Pará, que constituem uma opção viável e sustentável para a recuperação e utilização contínua de áreas alteradas. O taperebá é um dos frutos comercializados nas feiras de produtores, nas redes de supermercados e em mini-boxes na forma in natura e em forma de polpa congelada mantida sob refrigeração. É considerado fonte de vitaminas do complexo B como $\mathrm{B} 1$ (tiamina) e $\mathrm{B} 2$ (riboflavina), vitamina $\mathrm{C}$ e, principalmente, vitamina A (LEDERMAN et al., 2008).

A crescente demanda de produtos do gênero Spondias tem destacado o potencial socioeconômico de exploração da espécie. Atendendo às expectativas de melhor qualidade de vida e renda no campo e das agroindústrias de processamento é necessário empenho em pesquisas que viabilizem a exploração comercial visto que o taperebá se destaca com grande potencial produtivo e nutritivo dentre os frutos amazônicos (CASSIMIRO et al., 2009).

Segundo Nunes et al. (2011) a vida pós-colheita do taperebá é curta pois constituem-se de frutos delicados,que mesmo sob refrigeração são altamente perecíveis e suscetíveis a fungos que causam rápida deterioração, fator que implica em preço elevado e problemas relacionados ao processamento, embalagem, transporte e conservação. Como os frutos de taperebá são consumidos na sua integridade, tanto ao natural como processado (polpa), deve-se utilizar, na sua conservação, produtos naturais e biodegradáveis e que não alterem seu sabor, sua cor e seu aroma característicos.

Estudos têm demonstrado a eficiência do 1metilciclopropeno (1-MCP) em estender a vida póscolheita de frutos, inibindo a ação do etileno, hormônio vegetal chave envolvido nos processos metabólicos do amadurecimento, sem comprometer a qualidade sensorial dos frutos (FANTE et al., 2013).

Diante de uma literatura deficiente em pesquisas envolvendo frutos tropicais considerados "exóticos", torna-se de fundamental importância estabelecer parâmetros de conservação visando à expansão desses frutos para novos mercados. Diante disso, este trabalho foi realizado com o objetivo de estudar a influência do 1-MCP sobre a conservação e a qualidade de taperebás mantidos sob refrigeração visando maior tempo de comercialização na forma in natura.

\section{Material e Métodos}

O presente trabalho foi conduzido no Laboratório de Tecnologia de Produtos da Universidade Federal do Pará, Campus Altamira-PA, com frutos de taperebá colhidos em estádio de maturação fisiológica alcançada (maduro), isto é, com coloração da polpa $100 \%$ amarela.

Os frutos foram colhidos de plantas matrizes, com idade produtiva de seis anos pertencentes ao banco de germoplasma da Embrapa Amazônia Oriental situada no município de Altamira-PA. $\mathrm{Na}$ colheita foram descartados os frutos com defeitos fisiológicos, injúrias mecânicas e ou acometidos por pragas e doenças.

Os frutos foram acondicionados em caixas térmicas contendo água e gelo e transportados até o laboratório onde foram lavados em água corrente e sanitizados em solução clorada a $5 \%$ por três minutos, secos sob temperatura ambiente e ventilação, então logo após, submetidos aos tratamentos com 1-MCP, produto comercial SmartFresh $^{\circledR}$.

Os tratamentos utilizados envolveram doses de 0 (testemunha), 50, 100 e $150 \mathrm{mg} \mathrm{L}^{-1}$ de $1-\mathrm{MCP}$, obtido de uma formulação em pó contendo $0,14 \%$ deste produto. Depois de calculada a concentração necessária para cada tratamento, a formulação foi solubilizada individualmente em água em recipientes herméticos à temperatura ambiente e, posteriormente, cada solução foi acondicionada aberta juntamente com os frutos em caixas de isopor, com volume de 80 litros, com imediato fechamento destas. Os frutos ficaram expostos ao tratamento por 12 horas à temperatura de $23^{\circ} \mathrm{C}( \pm 2)$. Finalizado os tratamentos, os frutos foram acondicionados em embalagem de poliestireno expandido + filme de cloreto de polivinila e armazenados em refrigerador a $10 \pm 2^{\circ} \mathrm{C}$ e $85-90 \%$ de UR, por um período de 12 dias.

O delineamento experimental adotado foi inteiramente casualizado, com esquema fatorial $4 \times 5$, sendo (quatro concentrações de 1-MCP e cinco tempos de avaliação: 0, 3, 6, 9 e 12 dias), com cinco repetições e a parcela experimental composta por bandejas com dez frutos.

A cada três dias as amostras de cada tratamento foram avaliadas quanto às seguintes características: Perda de massa fresca, determinada com auxílio de balança semi-analitica. Os resultados foram expressos em porcentagem, considerando-se a diferença entre a massa inicial dos frutos e aquela obtida a cada intervalo de tempo de amostragem a partir da seguinte equação: $\mathrm{PMF}=(\mathrm{MFI}-\mathrm{MFF}) \times 100$, em que, PMF, perda de massa fresca (\%); MFI, massa fresca inicial (g); MFF, massa fresca final $(\mathrm{g})$; os dados foram transformados em perda de massa acumulada (\%).

A firmeza dos frutos foi mensurada com penetrômetro tipo Fruit Pressure Tester TR, com ponteira de $6 \mathrm{~mm}$ de diâmetro; foram feitas duas leituras na região equatorial dos frutos com casca em lados opostos sendo os resultados expressos em Newtons (N).

O teor de sólidos solúveis (SS) foi determinado por leitura em refratômetro digital com correção automática 
de temperatura (escala de 0 a $32 \%$ ), a partir da polpa macerada, homogeneizada e filtrada, sendo os resultados expressos em ${ }^{\circ}$ Brix.

A acidez Titulável (AT) foi determinada por meio de titulação com solução de $\mathrm{NaOH}$ a $0,1 \mathrm{~N}$ e indicador fenolftaleína; expressa em $\mathrm{g}$ de ácido cítrico/100g de polpa conforme preconizado por AOAC (2012). Da polpa diluída foi determinado o $\mathrm{pH}$ (5g de polpa/50ml de água destilada), utilizando um potenciômetro digital com membrana de vidro, conforme AOAC (2012).

O conteúdo de vitamina $\mathrm{C}$ foi determinado pelo método proposto por Chen e Wang (2002) em espectrofotômetro a $525 \mathrm{~nm}$, sendo os resultados expressos na curva de calibração em g. $100 \mathrm{~g}-1$ de ácido ascórbico. O índice de maturação SS/AT foi determinado pelo quociente entre os valores de sólido solúveis e a acidez titulável.

Os resultados de cada análise foram submetidos à análise de variância $(\mathrm{p}<0,05)$ e as médias comparadas pelo teste de Tukey, ao nível de $5 \%$ de probabilidade através do software estatístico Assistat 7.7 versão beta.

\section{Resultados e Discussão}

Houve interação significativa a nível de 5\% (p>5,0) para todas as características analisadas tanto ao longo do tempo de armazenamento quanto nas concentrações de 1-MCP avaliadas.

A perda de massa fresca pode ser apontada como a principal causa da deterioração na pós-colheita, deve-se ressaltar que a perda de massa fresca implica não somente em redução quantitativa, mas também em perda de aparência, textura e qualidade nutricional dos alimentos (CHITARRA; CHITARRA, 2005).

De acordo com os dados apresentados na Tabela 1 , observa-se que houve aumento gradual da perda de massa fresca em todos os tratamentos, ao longo do tempo de armazenamento. Os frutos representados pelos tratamentos testemunha e $50 \mathrm{mg}$ L-1 de 1 -MCP não diferiram entre si durante todo o período experimental e apresentaram as maiores reduções principalmente após o sexto dia de armazenamento, chegando ao fim de doze dias com percentual superior a $6 \%$. As concentrações de 100 e 150 mg L-1 de 1-MCP mostraram pouca redução até o sexto dia de armazenamento quando o percentual médio verificado ficou em torno de $2,25 \%$ chegando a menos de $4 \%$ ao fim do experimento (Tabela 1 ).

Os resultados dessa pesquisa corroboram com os apresentados por Plainsirichai et al. (2010) e Campos et al. (2011) onde maiores concentrações de 1-MCP associado ao armazenamento refrigerado foram eficientes em reduzir a perda de massa fresca em jambos e mangabas, frutas caracterizadas como de clima tropical, semelhante ao taperebá. A firmeza dos frutos apresentou variação entre os tratamentos no decorrer do tempo de armazenamento (Tabela 2).

O tratamento testemunha foi mais afetado, com redução expressiva logo após o terceiro dia de análise verificando média de $33,5 \mathrm{~N}$. Independente da concentração de 1-MCP a firmeza dos frutos só foi alterada após seis dias de armazenamento quando notase uma redução de até $15 \mathrm{~N}$ nos valores médios, tendo as concentrações de 100 e $150 \mathrm{mg} \mathrm{L}^{-1}$, as menores reduções (Tabela 2).

Tabela 1. Valores médios sobre a perda de massa fresca (\%) em taperebás tratados com 1-MCP e armazenados sob refrigeração por 12 dias.

\begin{tabular}{lccccc}
\hline \multirow{2}{*}{ Tratamentos 1-MCP } & \multicolumn{5}{c}{ Perda de massa fresca (\%) } \\
\cline { 2 - 5 } & 0 & 3 & 6 & 9 & 12 \\
\hline Testemunha & $0,0 \mathrm{aA}$ & $1,87 \mathrm{bA}$ & $3,78 \mathrm{cA}$ & $5,04 \mathrm{dA}$ & $6,19 \mathrm{eA}$ \\
$50 \mathrm{mg} \mathrm{L}^{-1}$ & $0,0 \mathrm{aA}$ & $1,75 \mathrm{bA}$ & $3,83 \mathrm{cA}$ & $4,89 \mathrm{bA}$ & $6,08 \mathrm{bA}$ \\
$100 \mathrm{mg} \mathrm{L}^{-1}$ & $0,0 \mathrm{aA}$ & $1,37 \mathrm{bB}$ & $2,25 \mathrm{cB}$ & $2,93 \mathrm{~dB}$ & $3,85 \mathrm{eB}$ \\
$150 \mathrm{mg} \mathrm{L}^{-1}$ & $0,0 \mathrm{aA}$ & $1,34 \mathrm{bB}$ & $2,14 \mathrm{cB}$ & $3,03 \mathrm{~dB}$ & $3,79 \mathrm{eB}$ \\
\hline \multicolumn{5}{c}{$\mathrm{CV}(\%)=3,84$}
\end{tabular}

Médias seguidas pela mesma letra, minúscula na linha (dias de armazenamento) e maiúscula na coluna (concentrações de 1-MCP), diferem significativamente entre si, a $5 \%$ de probabilidade, pelo teste de Tukey.

Tabela 2. Valores médios sobre a firmeza da polpa $(\mathrm{N})$ em taperebás tratados com 1-MCP e armazenados sob refrigeração por 12 dias.

\begin{tabular}{lccccc}
\hline \multirow{2}{*}{ Tratamentos 1-MCP } & \multicolumn{5}{c}{ Firmeza da polpa (N) } \\
\cline { 2 - 6 } & 0 & 3 & 6 & 9 & 12 \\
\hline Testemunha & $42,6 \mathrm{aA}$ & $39,8 \mathrm{aA}$ & $33,5 \mathrm{bB}$ & $24,3 \mathrm{cB}$ & $13,2 \mathrm{dC}$ \\
$50 \mathrm{mg} \mathrm{L}^{-1}$ & $42,6 \mathrm{aA}$ & $40,8 \mathrm{aA}$ & $38,6 \mathrm{abA}$ & $29,8 \mathrm{bB}$ & $17,8 \mathrm{cB}$ \\
$100 \mathrm{mg} \mathrm{L}^{-1}$ & $42,6 \mathrm{aA}$ & $41,3 \mathrm{aA}$ & $39,4 \mathrm{aA}$ & $30,6 \mathrm{bA}$ & $25,9 \mathrm{cA}$ \\
$150 \mathrm{mg} \mathrm{L}^{-1}$ & $42,6 \mathrm{aA}$ & $40,7 \mathrm{aA}$ & $39,5 \mathrm{aA}$ & $30,8 \mathrm{bA}$ & $25,6 \mathrm{cA}$ \\
\hline \multicolumn{5}{c}{$\mathrm{CV}(\%)=5,19$} \\
\hline
\end{tabular}

Médias seguidas pela mesma letra, minúscula na linha (dias de armazenamento) e maiúscula na coluna (concentrações de 1-MCP), diferem significativamente entre si, a $5 \%$ de probabilidade, pelo teste de Tukey. 
Morais et al. (2007) e Pinto et al. (2013) também verificaram os efeitos positivos do 1-MCP sobre a firmeza de frutos tropicais como o sapoti e o camucamu. A qualidade do taperebá em sua forma in natura está diretamente relacionada à firmeza da polpa e ao conteúdo de sólidos solúveis (açucares), assim, faz-se necessário o controle destes atributos no armazenamento pós-colheita visando a aceitação dos consumidores.

O amolecimento da polpa é a modificação mais perceptível durante o armazenamento, sendo um processo altamente sensível à presença de etileno, que mesmo em baixas concentrações é capaz de levar à rápida perda de firmeza do fruto (MORETTI, 2007), sendo diferente do observado para este experimento.

Santos et al. (2006) explicam que o aumento do $\mathrm{pH}$ na pós-colheita é um indicativo de deterioração devido ao consumo dos ácidos orgânicos para as reações próprias da maturação, senescência e pelo metabolismo respiratório dos frutos elevando desta forma os valores de $\mathrm{pH}$, fato este observado neste trabalho (Tabela 3). De acordo com o verificado na Tabela 3 , observa-se que os valores de $\mathrm{pH}$ aumentaram gradativamente com o tempo de armazenamento em todos os tratamentos com médias variando de 3,75 a 4,55 do primeiro ao décimo segundo dia, respectivamente.

Os frutos dos tratamentos testemunha e os frutos submetidos à concentração de $50 \mathrm{mg} \mathrm{L}^{-1}$ de $1-\mathrm{MCP}$ apresentaram os maiores valores durante todo o período experimental ao passo que as concentrações de 100 e
$150 \mathrm{mg} \mathrm{L}^{-1}$ de 1-MCP além de não diferirem entre si pouco influenciaram nos níveis de $\mathrm{pH}$ durante o armazenamento permanecendo com médias abaixo de $4,0 \mathrm{pH}$ ao fim de doze dias.

Os valores médios para o conteúdo de SS, verificados neste trabalho, oscilaram entre 6,5 e 10,8 ${ }^{\circ}$ Brix (Tabela 4) durante o período experimental. Bastos et al. (2008) encontraram valores dentro dessa faixa (7,2 a 10,6 ${ }^{\circ}$ Brix) quando avaliaram a polpa de taperebás.

Para Chitarra e Chitarra (2005) o teor de sólidos solúveis é utilizado como uma medida indireta da quantidade de açúcares, haja vista que o processo de amadurecimento do fruto favorece o acúmulo desses açúcares na polpa. A sua medição não representa o teor exato dos açúcares, pois outras substâncias também estão dissolvidas tais como ácidos orgânicos, vitaminas, fenólicos, pectina, etc., entretanto, entre essas, os açúcares são as que possuem maior representação, chegando a constituir até $85-90 \%$ dos sólidos solúveis (SS).

Até o terceiro dia de análise não foi observado diferença entre os tratamentos e o tempo de armazenamento (Tabela 4). A partir do sexto dia de avaliação nota-se um acúmulo mais acentuado de açucares na polpa dos frutos do tratamento testemunha a qual diferiu significativamente das concentrações de 1MCP cujo acumulo nos teores de sólidos solúveis é menor e percebida somente ao nono dia de análise (Tabela 4).

Tabela 3. Valores médios sobre o potencial hidrogeônico $(\mathrm{pH})$ em taperebás tratados com 1-MCP e armazenados sob refrigeração por 12 dias.

\begin{tabular}{llllll}
\hline \multirow{2}{*}{ Tratamentos 1-MCP } & \multicolumn{5}{c}{ Potencial hidrogeônico $(\mathrm{pH})$} \\
\cline { 2 - 6 } & 0 & 3 & 6 & 9 & 12 \\
\hline Testemunha & $3,75 \mathrm{eA}$ & $3,92 \mathrm{dA}$ & $4,19 \mathrm{cA}$ & $4,37 \mathrm{bA}$ & $4,55 \mathrm{aA}$ \\
$50 \mathrm{mg} \mathrm{L}^{-1}$ & $3,75 \mathrm{eA}$ & $3,83 \mathrm{~dB}$ & $4,11 \mathrm{cA}$ & $4,32 \mathrm{bA}$ & $4,58 \mathrm{aA}$ \\
$100 \mathrm{mg} \mathrm{L}^{-1}$ & $3,75 \mathrm{dA}$ & $3,75 \mathrm{~dB}$ & $3,82 \mathrm{cB}$ & $3,90 \mathrm{bB}$ & $3,98 \mathrm{aB}$ \\
$150 \mathrm{mg} \mathrm{L}^{-1}$ & $3,75 \mathrm{dA}$ & $3,77 \mathrm{~dB}$ & $3,84 \mathrm{cB}$ & $3,88 \mathrm{bB}$ & $3,96 \mathrm{bB}$ \\
\hline
\end{tabular}

$\mathrm{CV}(\%)=0,63$

Médias seguidas pela mesma letra, minúscula na linha (dias de armazenamento) e maiúscula na coluna (concentrações de 1-MCP), diferem significativamente entre si, a $5 \%$ de probabilidade, pelo teste de Tukey.

Tabela 4. Valores médios sobre o conteúdo de sólidos solúveis ( ${ }^{\circ}$ Brix) em taperebás tratados com 1-MCP e armazenados sob refrigeração por 12 dias.

\begin{tabular}{lccccc}
\hline \multirow{2}{*}{ Tratamentos 1-MCP } & \multicolumn{5}{c}{ Sólidos solúveis $\left({ }^{\circ}\right.$ Brix $)$} \\
\cline { 2 - 6 } & 0 & 3 & 6 & 9 & 12 \\
\hline Testemunha & $6,5 \mathrm{cA}$ & $6,9 \mathrm{cA}$ & $8,7 \mathrm{bA}$ & $10,2 \mathrm{aA}$ & $6,4 \mathrm{cB}$ \\
$50 \mathrm{mg} \mathrm{L}^{-1}$ & $6,5 \mathrm{cA}$ & $6,7 \mathrm{cA}$ & $7,3 \mathrm{bB}$ & $8,9 \mathrm{aB}$ & $6,9 \mathrm{cB}$ \\
$100 \mathrm{mg} \mathrm{L}^{-1}$ & $6,5 \mathrm{cA}$ & $6,9 \mathrm{cA}$ & $7,1 \mathrm{cB}$ & $9,2 \mathrm{bB}$ & $10,8 \mathrm{aA}$ \\
$150 \mathrm{mg} \mathrm{L}^{-1}$ & $6,5 \mathrm{cA}$ & $6,6 \mathrm{cA}$ & $6,9 \mathrm{cB}$ & $8,6 \mathrm{bB}$ & $10,4 \mathrm{aA}$ \\
\hline \multicolumn{5}{c}{$\mathrm{CV}(\%)=2,21$}
\end{tabular}

Médias seguidas pela mesma letra, minúscula na linha (dias de armazenamento) e maiúscula na coluna (concentrações de 1-MCP), diferem significativamente entre si, a $5 \%$ de probabilidade, pelo teste de Tukey. 
Analisando o conteúdo de sólidos solúveis, Trevisan et al. (2013) e Silva et al. (2016) notaram menor acúmulo ao longo do tempo de armazenamento no conteúdo de SS na polpa de mamões "Golden" e atemóias "Gefner', quando foram tratados com esse bloqueador em relação a testemunha. No último dia de avaliação nota-se uma redução nos valores médios da testemunha e quando tratados com $50 \mathrm{mg} \mathrm{L}^{-1}$ de $1-\mathrm{MCP}$, tal fato deve-se ao intenso estádio de senescência em que se encontravam os frutos os quais passaram a utilizar os açucares como substrato no processo respiratório para se manterem vivos (Tabela 4).

A acidez titulável nos frutos mostrou comportamento regressivo com o tempo de armazenamento passando de $1,94 \mathrm{~g}$ de ácido cítrico/100g de polpa na instalação do experimento para menos de $1,50 \mathrm{~g}$ de ácido cítrico/100g de polpa ao fim de doze dias sob refrigeração (Tabela 5). Ao avaliar o efeito da temperatura de armazenamento na conservação do cajá, Kohatsu et al. (2011) também notaram decréscimos no conteúdo de ácidos orgânicos com valores abaixo a $1,00 \mathrm{~g}$ de ácido cítrico/100g de polpa ao fim do armazenamento.

A redução da acidez titulável durante o armazenamento deve-se ao metabolismo respiratório dos frutos, que tanto sintetiza quanto consome ácidos orgânicos, deste modo quanto menor o teor de acidez (ácidos orgânicos) na polpa dos frutos, maior será o grau de maturação/senescência dos vegetais (CHITARRA; CHITARRA, 2007).

Ainda de acordo com a Tabela 5, observa-se que a testemunha apresentou maior redução em todos os dias de análise diferindo das concentrações de 1-MCP já no terceiro dia de armazenamento. $\mathrm{O}$ menor consumo dos ácidos orgânicos nos frutos tratados com 1-MCP provavelmente está associado ao seu efeito bloqueador da síntese de etileno, inibindo a atuação desse gás e mantendo baixo o padrão respiratório dos frutos.

Frutos tropicais como o camu-camu também apresentaram menor consumo de ácidos orgânicos quando submetidos ao tratamento com 1-MCP em relação ao tratamento controle e a aplicação de etileno exógeno durante sua vida de prateleira (PINTO et al., 2013). Ao analisar o efeito isolado do 1-MCP destaca-se concentração de $150 \mathrm{mg} \mathrm{L}^{-1}$ a qual diferiu das demais a partir do terceiro dia de armazenamento apresentando um consumo mais lento dos ácidos orgânicos, indicando um estádio de senescência menos avançado (Tabela 5).

Os valores médios apresentados na Tabela 6 mostram que o teor de vitamina $\mathrm{C}$ ficou comprometido com o tempo de armazenamento, principalmente naqueles representados pelo tratamento testemunha cuja redução ultrapassou mais de $200 \mathrm{~g} / 100 \mathrm{~g}^{-1}$ ac. ascórbico polpa durante o período experimental.

Kohatsu et al. (2011) também notaram redução no teor de ácido ascórbico de cajás quando armazenados em diferentes condições de temperatura. Segundo Leme et al. (2007) a estabilidade das vitaminas nos alimentos pode ser afetada por inúmeros fatores, incluindo calor, luz, taxa respiratória, condições de armazenamento e $\mathrm{pH}$, sendo o ácido ascórbico um dos compostos vitamínicos que se degradam com maior facilidade.

A utilização do 1-MCP de modo geral promoveu menor degradação da vitamina $\mathrm{C}$ até o sexto dia de análise quando as médias verificadas entre os tratamentos variaram entre 1,613 e $1,621 \mathrm{~g} / 100 \mathrm{~g}^{-1}$ ac. ascórbico polpa, sem diferenças entre si. Ao final de doze dias somente os frutos expostos às concentrações de 100 e $150 \mathrm{mg} \mathrm{L}^{-1}$ de 1 -MCP apresentaram maiores quantidades de vitamina $\mathrm{C}$ em sua polpa em relação aos demais tratamentos (Tabela 6).

Medida importante para avaliar o grau de maturação de determinado fruto é o índice de maturação, comumente conhecido como Ratio que é definido pelo balanço entre os sólidos solúveis e a acidez titulável (SS/AT) (IENSEN et al., 2013).

Analisando a Tabela 7, nota-se que os valores médios sobre o ratio apresentaram variações no decorrer do período experimental, em suma os frutos do tratamento testemunha foram estatisticamente inferiores às concentrações de 1-MCP, apresentando aumento mais expressivo e atingindo pico de 10,04 no nono dia de avaliação com posterior redução no último dia de armazenamento. Essa redução observada no último dia de armazenamento evidencia um estádio de senescência mais avançado dos frutos em função do decréscimo no teor de açúcares e de ácidos orgânicos na polpa dos frutos.

Tabela 5. Valores médios sobre a acidez titulável (g de ácido cítrico/100g de polpa) em taperebás tratados com 1-MCP e armazenados sob refrigeração por 12 dias.

\begin{tabular}{lccccc}
\hline \multirow{2}{*}{ Tratamentos 1-MCP } & \multicolumn{5}{c}{ Acidez titulável (g de ácido cítrico/100g de polpa) } \\
\cline { 2 - 5 } & 0 & 3 & 6 & 9 & 12 \\
\hline Testemunha & $1,94 \mathrm{dA}$ & $1,62 \mathrm{bB}$ & $1,47 \mathrm{cC}$ & $1,31 \mathrm{cC}$ & $1,08 \mathrm{cC}$ \\
$50 \mathrm{mg} \mathrm{L}^{-1}$ & $1,94 \mathrm{dA}$ & $1,73 \mathrm{cA}$ & $1,59 \mathrm{bB}$ & $1,42 \mathrm{cB}$ & $1,36 \mathrm{aB}$ \\
$100 \mathrm{mg} \mathrm{L}^{-1}$ & $1,94 \mathrm{dA}$ & $1,77 \mathrm{cA}$ & $1,58 \mathrm{bB}$ & $1,45 \mathrm{cB}$ & $1,39 \mathrm{aB}$ \\
$150 \mathrm{mg} \mathrm{L}^{-1}$ & $1,94 \mathrm{dA}$ & $1,81 \mathrm{cA}$ & $1,73 \mathrm{bA}$ & $1,61 \mathrm{cA}$ & $1,47 \mathrm{aA}$ \\
\hline
\end{tabular}

Médias seguidas pela mesma letra, minúscula na linha (dias de armazenamento) e maiúscula na coluna (concentrações de 1-MCP), diferem significativamente entre si, a $5 \%$ de probabilidade, pelo teste de Tukey. 
Tabela 6. Valores médios sobre o teor de vitamina $\mathrm{C}(\mathrm{mg} / 100 \mathrm{~g}$ ac. ascórbico polpa) em taperebás tratados com 1-MCP e armazenados sob refrigeração por 12 dias.

\begin{tabular}{lccccc}
\hline \multirow{2}{*}{ Tratamentos 1-MCP } & \multicolumn{5}{c}{ Vitamina C (mg/100g ac. ascórbico polpa) } \\
\cline { 2 - 6 } & 0 & 3 & 6 & 9 & 12 \\
\hline Testemunha & $1,674 \mathrm{aA}$ & $1,584 \mathrm{bB}$ & $1,531 \mathrm{cB}$ & $1,493 \mathrm{~dB}$ & $1,470 \mathrm{eB}$ \\
$50 \mathrm{mg} \mathrm{L}^{-1}$ & $1,674 \mathrm{aA}$ & $1,635 \mathrm{bA}$ & $1,613 \mathrm{cA}$ & $1,538 \mathrm{~dB}$ & $1,492 \mathrm{eB}$ \\
$100 \mathrm{mg} \mathrm{L}^{-1}$ & $1,674 \mathrm{aA}$ & $1,640 \mathrm{bA}$ & $1,616 \mathrm{cA}$ & $1,544 \mathrm{~dB}$ & $1,529 \mathrm{eA}$ \\
$150 \mathrm{mg} \mathrm{L}^{-1}$ & $1,674 \mathrm{aA}$ & $1,643 \mathrm{bA}$ & $1,621 \mathrm{cA}$ & $1,556 \mathrm{~dB}$ & $1,534 \mathrm{eA}$ \\
\hline
\end{tabular}

Médias seguidas pela mesma letra, minúscula na linha (dias de armazenamento) e maiúscula na coluna (concentrações de 1-MCP), diferem significativamente entre si, a 5\% de probabilidade, pelo teste de Tukey.

Tabela 7. Valores médios sobre o índice de maturação (SS/AT) em taperebás tratados com 1-MCP e armazenados sob refrigeração por 12 dias.

\begin{tabular}{lccccc}
\hline \multirow{2}{*}{ Tratamentos 1-MCP } & \multicolumn{5}{c}{ Índice de maturação (SS/AT) } \\
\cline { 2 - 6 } & 0 & 3 & 6 & 9 & 12 \\
\hline Testemunha & $6,38 \mathrm{dA}$ & $8,76 \mathrm{cB}$ & $9,28 \mathrm{bB}$ & $10,04 \mathrm{aC}$ & $8,44 \mathrm{bB}$ \\
$50 \mathrm{mg} \mathrm{L}^{-1}$ & $6,38 \mathrm{eA}$ & $7,51 \mathrm{dA}$ & $8,22 \mathrm{cA}$ & $9,29 \mathrm{bB}$ & $10,02 \mathrm{aB}$ \\
$100 \mathrm{mg} \mathrm{L}^{-1}$ & $6,38 \mathrm{eA}$ & $7,38 \mathrm{dA}$ & $8,13 \mathrm{cA}$ & $9,17 \mathrm{bB}$ & $9,92 \mathrm{aB}$ \\
$150 \mathrm{mg} \mathrm{L}^{-1}$ & $6,38 \mathrm{eA}$ & $7,45 \mathrm{dA}$ & $8,15 \mathrm{cA}$ & $8,88 \mathrm{bA}$ & $9,27 \mathrm{aA}$ \\
\hline \multicolumn{5}{c}{$\mathrm{CV}(\%)=8,32$} \\
\hline
\end{tabular}

Médias seguidas pela mesma letra, minúscula na linha (dias de armazenamento) e maiúscula na coluna (concentrações de 1-MCP), diferem significativamente entre si, a 5\% de probabilidade, pelo teste de Tukey.

Os tratamentos com 1-MCP diferiram entre si após o sexto dia de armazenamento, contudo, não foi verificada redução nos valores durante o período experimental sendo o pico máximo de 10,02 verificado na dosagem de $50 \mathrm{mg} \mathrm{L}^{-1}$ de 1-MCP, no décimo segundo dia (Tabela 7). Para Carvalho et al. (2008) maiores valores no índice de maturação é um indicativo de amadurecimento mais acelerado, deste modo, maiores dosagens de 1-MCP contribuirão para retardar os processos metabólicos que envolvem o amadurecimento/senescência dos taperebás, principalmente quando submetidos a $150 \mathrm{mg} \mathrm{L}^{-1}$ de 1MCP, cujo pico máximo ao fim de doze dias foi de apenas 9,27 (Tabela 7).

De modo geral os valores médios da relação SS/AT ficaram ao longo do tempo de armazenamento abaixo do mínimo exigido, conforme o Padrão de identidade e qualidade (PIQ) para frutos do gênero Spondia, que é de 10,0 conforme preconizado por Santos et al. (2010). Esta relação é altamente dependente do mercado consumidor, sendo que para o consumo brasileiro a preferência é por uma relação maior verificada por altos teores de SS e baixa acidez, diferente do observado nos frutos de taperebá cujo teor de acidez dos frutos é superior ao de açucares.

\section{Conclusões}

A vida de prateleira dos taperebás na forma in natura foi significativamente preservada ao longo do tempo de armazenamento quando houve o tratamento com 1MCP.
A concentração de $150 \mathrm{mg} \mathrm{L}^{-1}$ de 1-MCP favoreceu os melhores resultados para todas as características avaliadas, sendo, portanto, a recomendada para a conservação desse fruto nas condições de refrigeração.

\section{Referências Bibliográficas}

AOAC. ASSOCIATION OF OFFICIAL ANALYTICAL CHEMISTRY. Official methods of analysis of the Association of Official Analytical Chemistry. Washington: AOAC, 2012.

BASTOS, C. T. R. M.; LADEIRA, T. M. S.; ROGEZ, H.; PENA, R. S. Estudo da eficiência da pasteurização da polpa de taperebá (Spondias mombin). Alimentos e Nutrição, Araraquara-SP, v. 19, n. 2, p. 123-131, 2008.

CAMPOS, R. P.; KNOCH, B.; HIANE, P. A.; RAMOS, M. I. L.; FILHO, M. M. R. 1-MCP em mangabas armazenadas em temperatura ambiente e a $11^{\circ} \mathrm{C}$. Revista Brasileira de Fruticultura, Jaboticabal-SP, Volume Especial, n. 3, p. 206212, 2011

CARVALHO, P. C. L.; RITZINGER, R.; SOARES FILHO, W. S.; LEDO, C. A. S. Características morfológicas, físicas e químicas de frutos de populações de umbu-cajazeira no Estado da Bahia. Revista Brasileira de Fruticultura, Jaboticabal-SP, v. 30, n. 1, p. 140-147, 2008.

CASSIMIRO, C. M.; MACÊDO, L. S.; MENINO, I. B. Avaliação de acessos de cajazeira (Spondias mombin) do Banco Ativo de Germoplasma da Emepa, PB. Tecnologia e Ciência Agropecuária, João Pessoa-PB, v. 3, n. 3, p. 01-06, 2009. 
CHEN, J.; WANG, X. Experimental instruction of plant physiology. South China University of Technology Press, Guangzhou, CHN, v. 1, n. 3, p. 124, 2002.

ChITARra, M. I. F.; CHITARRA, A. B. Pós-colheita de frutas e hortaliças: fisiologia e manuseio. 2. ed. Lavras-MG: UFLA, 2005. $785 \mathrm{p}$.

FANTE, C. A.; BOAS, A. C. V.; COSTA, A. C.; SILVA, E. P.; OLIVEIRA, M. C.; LIMA, L. C. O. 1-MCP nos aspectos fisiológicos e na qualidade pós-colheita de maçãs Eva durante o armazenamento refrigerado. Ciência Rural, Santa MariaRS, v. 43, n. 12, p. 2142-2147, 2013.

IENSEN, D.; SANTOS, I. V.; QUAST. E.; QUAST, L. B.; RAUPP, D. S. Desenvolvimento de Geleia de Kiwi: Influência da Polpa, Pectina e Brix na Consistência. UNOPAR Científica Ciências Biológicas e da Saúde, Londrina-PR, v. 4, n.1, p. 56-64, 2013.

KOHATSU, D. S.; ZUCARELLI, V.; BRAMBILIA, W. P.; EVANGELISTA, R. M. Qualidade de frutos de cajá-manga armazenados sob diferentes temperaturas. Revista Brasileira de Fruticultura. Jaboticabal-SP, Volume Especial, n. 4, p. 344-349, 2011.

LEDERMAN, I. E.; LIRA JÚNIOR, J. S.; SILVA JÚNIOR, J. F. Spondias no Brasil: umbu, cajá e espécies afins. (Ed). Recife-PE: IPA-UFRPE, 2008. 180 p.

LEME, A. C.; GROPPO, V. D.; ROMERO, A. C.; SPOTO, M. H. F.; JACOMINO, A. P. Influência do uso de películas comestíveis em laranja 'Pera' minimamente processada. Boletim do CEPPA, Curitiba-PR, v. 25, n. 1, p. 15-24, 2007.

MORAIS, P. L. D.; LIMA, L. C. O.; ALVES, R. E.; DONIZETI, J.; ALVES, A. P. Conservação pós-colheita de sapoti submetido a diferentes doses de 1-metilciclopropeno. Revista Ceres, Lavras-MG, v. 54, n. 316, p. 517-525, 2007.

MORETTI, C. L. Alterações metabólicas. In: MORETTI, C. L. Manual de processamento mínimo de frutas e hortaliças. Brasília-DF: Embrapa Hortaliças/SEBRAE, 2007. p.41-77.
NUNES, A. R.; SANTANA, F. F.; GOMES, R. L. F.; LPES, A. A.; PEREIRA, M. M. G.; SOARES, E. B. Stratified mass selection of promising Spondias mombin clones in a commercial crop. Crop Breeding and Applied Biotechnology, Brasília- DF, v.11, n. 2, p. 141-148, 2011.

PLAINSIRICHAI, M.; TRINOK, U.; TURNER, D. W. 1methylcyclopropene (1-MCP) reduces water loss and extends shelf life of fruits of Rose apple (Syzygium jambos Alston) cv. Tabtim Chan. Fruits, Xangai, CHN, v. 65, n. 4, p. 133-140, 2010 .

PINTO, P. M.; JACOMINO, A. P.; SILVA, S. R. da; AMDRADE, C. A. W. Ponto de colheita e maturação de frutos de camu-camu colhidos em diferentes estádios. Pesquisa Agropecuária Brasileira, Brasília-DF, v. 48, n. 6 , p. 605-612, 2013.

SANTOS, C. M.; VILAS BOAS, E. V. B.; BOTREL, N.; PINHEIRO, A. C. M. Influência da atmosfera controlada sobre a vida pós-colheita e qualidade de banana 'prata anã'. Ciência e Agrotecnologia, Lavras-MG, v. 30, n. 2, p. 317322, 2006.

SANTOS, M. B.; CARDOSO, R. L.; FONSECA, A. A. O.; CONCEIÇÃO, M. N. Caracterização e qualidade de frutos de umbu-cajá (Spondias tuberosa x S. mombin) provenientes do Recôncavo Sul da Bahia. Revista Brasileira de Fruticultura, Jaboticabal-SP, v. 32, n. 3, p. 1089-1097. 2010.

SILVA, G. M. C.; SILVA, M. P. S.; BIAZATTI, M. A.; SANTOS, C.; SILVA, N. M.; MIZOBUTSI, G. P. Uso do 1MCP e atmosfera modificada na pós-colheita de atemóia "Gefner". Revista Brasileira de Ciências Agrárias, RecifePE, v. 11, n. 2, p. 67-72, 2016.

TREVISAN, M. J.; JACOMINO, A. P.; CUNHA JUNIOR, L. C.; ALVES, R. F. Aplicação de 1-metilciclopropeno associado ao etileno para minimizar seus efeitos na inibição do amadurecimento do mamão "Golden". Revista Brasileira de Fruticultura. Jaboticabal-SP, v. 35, n. 2, p. 384-390, 2013. 